This item was submitted to Loughborough's Research Repository by the author.

Items in Figshare are protected by copyright, with all rights reserved, unless otherwise indicated.

\title{
Individual differences in children's understanding of inversion and arithmetical skill
}

PLEASE CITE THE PUBLISHED VERSION

http://onlinelibrary.wiley.com/doi/10.1348/000709905X39125/abstract

PUBLISHER

Wiley-Blackwell @ The British Psychological Society

VERSION

AM (Accepted Manuscript)

LICENCE

CC BY-NC-ND 4.0

REPOSITORY RECORD

Gilmore, Camilla K., and Peter Bryant. 2019. "Individual Differences in Children's Understanding of Inversion and Arithmetical Skill”. figshare. https://hdl.handle.net/2134/8759. 
This item was submitted to Loughborough's Institutional Repository (https://dspace.lboro.ac.uk/) by the author and is made available under the following Creative Commons Licence conditions.

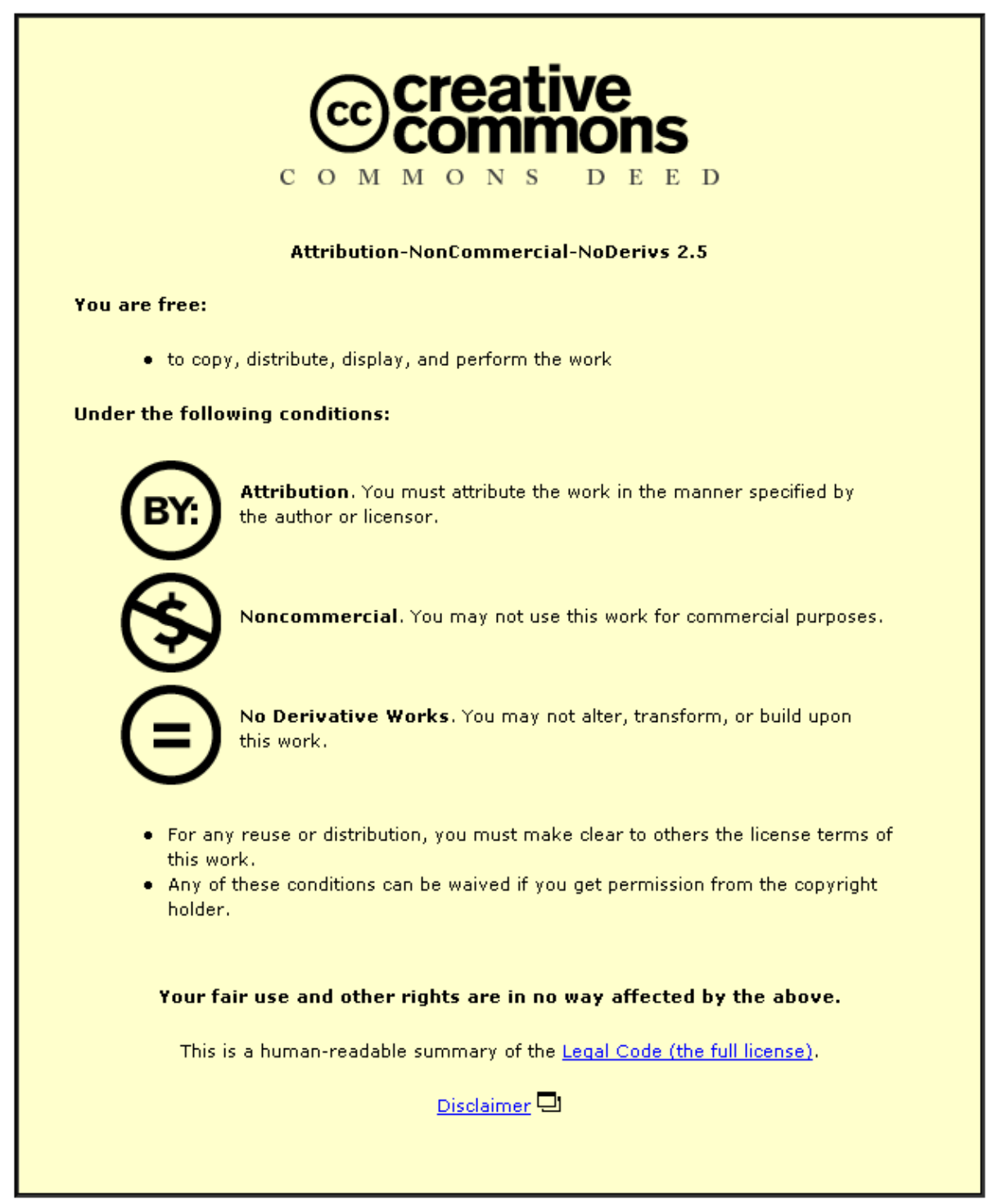

For the full text of this licence, please go to: http://creativecommons.org/licenses/by-nc-nd/2.5/ 
Running head: INDIVIDUAL DIFFERENCES IN INVERSION

Individual differences in children's understanding of inversion and arithmetical skill Camilla K. Gilmore and Peter Bryant University of Oxford

This paper was published in British Journal of Educational Psychology (2006), 76, 309-331. DOI:10.1348/000709905X39125 


\begin{abstract}
Background and aims: In order to develop arithmetic expertise, children must understand arithmetic principles, such as the inverse relationship between addition and subtraction, in addition to learning calculation skills. We report two experiments that investigate children's understanding of the principle of inversion and the relationship between their conceptual understanding and arithmetical skills.
\end{abstract}

Sample: 127 children from primary schools took part in the study. The children were from two age groups $(6-7$ and $8-9$ years).

Methods: Children's accuracy on inverse and control problems in a variety of presentation formats and in canonical and non-canonical forms was measured. Tests of general arithmetic ability were also administered.

Results: Children consistently performed better on inverse than control problems, which indicates that they could make use of the inverse principle. Presentation format affected performance: picture presentation allowed children to apply their conceptual understanding flexibly regardless of the problem type, while word problems restricted their ability to use their conceptual knowledge. Cluster analyses revealed three subgroups with different profiles of conceptual understanding and arithmetical skill. Children in the 'high ability' and 'low ability' groups showed conceptual understanding that was in-line with their arithmetical skill whilst a third group of children had more advanced conceptual understanding than arithmetical skill. 
Conclusions: The three subgroups may represent different points along a single developmental path or distinct developmental paths. The discovery of the existence of the three groups has important consequences for education. It demonstrates the importance of considering the pattern of individual children's conceptual understanding and problem solving skills. 
Individual differences in children's understanding of inversion and arithmetical skill

An important distinction in the study of children's arithmetical understanding is between being able to carry out a computation and being able to use underlying principles of mathematical relations. In learning arithmetic children need to develop understanding of principles such as the inverse relationship between addition and subtraction and the commutative nature of addition. Once children understand these principles they can, in principle, use their knowledge to make computation simpler: for example they could adopt the strategy of counting on from the larger addend as a result of understanding commutativity (Baroody \& Gannon, 1984; Cowan \& Renton, 1996) or decompose numbers because they have begun to understand the principle of inversion (Bryant, Christie, \& Rendu, 1999). In some situations children can use their conceptual understanding to eliminate the need for computation completely: they might, for example, use their understanding of the relationship between addition and subtraction to solve inversion problems (e.g. $a+b-b=?)$.

One of the key conceptual relationships that children must acquire as they begin to learn arithmetic is the inverse relationship between addition and subtraction. Piaget (1952) described inversion as a basic type of reversibility - a key property of cognitive structures. He suggested that children cannot be said to have a true understanding of addition and subtraction until they can coordinate these operations.

Piaget and Moreau (1977/ 2001) examined children's understanding of this principle using a concrete task involving bricks. The child selected a number of bricks ('a') which they hid from the experimenter. They were then told to add a number ('b') of bricks to it and then tell the experimenter how many they had in total ('c'). The experimenter was then able to calculate how many bricks the child initially selected 
('a') and then asked the child how they had been able to work this out. The child was only considered to understand inversion if they could explain this by realizing that if a $+\mathrm{b}=\mathrm{c}$ then $\mathrm{c}-\mathrm{b}=\mathrm{a}$.

Bryant et al (1999) point out, however, that this is a strong test of inversion and may be too stringent. To pass this test, not only must the children understand the inverse relationship between addition and subtraction, but they must also realize that this is relevant to the problem and that the experimenter has made use of it. Children may find it difficult to make this inference, even though they understand the inverse relationship between addition and subtraction itself. Thus a more direct test of children's understanding of the inverse relationship has been developed by presenting children with problems of the form $\mathrm{a}+\mathrm{b}-\mathrm{b}=$ (e.g. Bisanz, LeFevre, \& Gilliland, 1989; Bryant et al. 1999; Klein and Bisanz, 2000; Rasmussen, Ho, \& Bisanz, 2003; Siegler \& Stern, 1998; Starkey \& Gelman, 1982; Stern, 1992; Vilette, 2002). With this type of test we can observe whether or not children solve the problem directly without calculation, by making use of a procedural shortcut based directly on conceptual understanding of the inverse relationship.

The use of conceptually based shortcut strategies is one way to reveal the extent that children understand and can use conceptual knowledge (Bisanz \& LeFevre, 1990). Knowledge of the inverse relationship between addition and subtraction implies that adding and then subtracting the same quantity will leave the initial quantity unchanged (Klein and Bisanz, 2000). If children understand the inverse principle, then they can choose to use a shortcut strategy to solve problems ( such $a \mathrm{a}+\mathrm{b}-\mathrm{b}=\mathrm{a}$ ) rather than using computation and thus solve problems that would otherwise be computationally complex. If we design the problems to be difficult then accuracy will be low when children are using computation rather than 
the inversion-based shortcut (Rasmussen et al. 2003). Thus if children are more accurate at solving the inverse problems than the control problems this implies they have made use of the conceptually based shortcut which reveals that they must understand this inverse relationship. Use of this shortcut does not necessarily imply conscious awareness of the relationship. In a microgenetic study of inversion by Siegler and Stern (1998) a large majority of children used the inversion-based shortcut at an implicit level some time before they were able to explicitly report using it. Whether or not a child can verbally report using a conceptually-based shortcut, its use does imply that at some level the child must understand the concept underlying the shortcut.

There is some evidence of a separation between the ability to use conceptual principles and computational skill. Bryant et al. (1999) compared children's performance on three-term inverse problems (e.g. $14+7-7)$ and matched control problems (e.g. $9+9-4$ ). Children aged 5 to 8 years scored higher for inversion than control problems which indicates that they could make use of the inverse principle. However factor analysis revealed that there was little relation between children's use of inversion and performance on control problems. This surprising result suggests that children's ability to understand and use the relationship between addition and subtraction is not related to their proficiency with these operations.

Canobi (2004) classified children according to their level of conceptual understanding of commutativity and inversion and their arithmetical skill. Children with more advanced conceptual understanding tended to have better problem solving skill. However there was wide variation, so that even in the least advanced problemsolving group nearly one fifth of the children were in the most advanced conceptual understanding group. 
Rasmussen et al. (2003) found a more mixed picture of the relationship between conceptual understanding of inversion and arithmetical skill in pre-school (5 -6 years) and Grade $1(6-7$ years $)$ children. For the pre-school group there was no evidence of a relationship between accuracy on inverse problems and arithmetical skill. Conceptual understanding was related to measures of visual-spatial working memory. However, for the Grade 1 children a correlation was found between conceptual understanding of inversion and accuracy on simple word problems.

We need to know more about the different ways in which children's conceptual understanding is related to their arithmetical skill across a range of age groups. If the ability to use arithmetical principles and calculation skills are independent of each other, it is possible that there are differences among children, and also among adults, in the patterns of their abilities. Some might show good conceptual understanding with poorer calculation skills, while others might show the reverse pattern.

Most developmental studies of arithmetic report age group results. For example, a number of authors have demonstrated that group mean performance on inverse problems is more accurate or faster than for control problems (Bisanz et al. 1989; Rasmussen et al. 2003; Stern, 1992). These results establish that some children must understand and use the inverse principle but it does not tell us about possible differences among children in the extent to which they use the principle and how their conceptual understanding relates to their arithmetical skill.

Cluster analysis is a useful technique that can be used to investigate these types of differences within a group. It sorts individuals into different subgroups according to their performance across a range of tasks. This method has rarely been used in studies of mathematical development. Canobi and colleagues (Canobi, 2004; 
Canobi, Reeve, \& Pattison, 1998, 2002, 2003) have used cluster analysis to group children according to their performance in conceptual or procedural tasks. These experimenters performed separate analyses for conceptual and procedural performance and then compared group membership across these dimensions. This approach does not directly examine individual differences in the relationship between conceptual understanding and problem solving. The most suitable way to examine this is to enter scores on conceptual and procedural measures into a single cluster analysis. This novel use of cluster analysis can highlight differences in the pattern of performance across understanding of concepts and computational skill to reveal whether groups exist with different profiles of behaviour.

Our aim was to perform this sort of analysis on children's understanding of the inversion principle. Children's use of inversion was investigated using a wider range of measures than have previously been used. We varied the position of the missing value within the sum, and also the presentation format of the problem.

Previous studies of children's understanding of inverse situations have all required children to solve problems, which we call canonical problems, by providing the answer to a three element problem (e.g. $15+7-7=$ ?). However children's ability to apply the inverse principle may be affected if they are given non-canonical as well as canonical problems. Problems can be presented with either the answer or one of the other elements missing (e.g. ? $+7-7=15 ; 7+?-7=15 ; 15+7-?=15)$ to determine how this affects children's use of the inverse concept. Within this paradigm children must use their understanding of the inverse relationship between addition and subtraction in a flexible manner. If children were to show reduced use of inversion for non-canonical problems this would suggest that they do not have a thorough understanding of this principle. The presentation format of a problem may 
affect children's ability to apply their conceptual understanding to a range of different canonical and non-canonical situations. So a range of formats was used (abstract digits, word problems, pictures) to investigate the impact of context on children's performance.

We shall report two experiments that investigate how different factors affect children's use of the inverse principle to solve problems. In the first experiment children were given inverse problems and matched control problems with either the first element or the last element of the sum missing. Problems were presented in digit format, as word problems or using a sequence of pictures describing events concerning items added to and removed from a box. These problem formats differ in the extent to which the problems are embedded in a meaningful context. The range of different problem types used allowed children's flexibility in applying the inverse principle to a range of situations to be assessed.

In the second experiment children's performance on problems presented using pictures was investigated in more detail. Younger and older children were presented with inverse and control problems using pictures with one of the four elements missing. In both studies the relationship between the children's use of the inverse principle and their general arithmetical skill was investigated. In particular cluster analysis was used to examine different profiles of performance on tests of inverse understanding and general problem solving.

Children's performance on these problems was analysed to address three main questions. First, are children able to apply the inverse principle to solve canonical and non-canonical problems and how does this ability develop with age? Second, how is children's performance on inverse problems related to scores on control problems and are there individual differences in the nature of this relationship? Finally, what is the 
effect of different types of problem presentation on children's success with inverse and control problems?

\section{Experiment 1}

Method

\section{Participants}

Sixty-eight participants (34 females and 34 males) with a mean age of $8 ; 11$ years (SD 3.32 months) took part in the study. All children spoke English as a first language and none was classified as having special needs.

Tasks

Children were presented with four-element inverse $(a+b-b=a)$ and control $(\mathrm{a}+\mathrm{b}-\mathrm{c}=\mathrm{d})$ problems. They were given 36 problems in total consisting of 12 different mathematical questions each presented in three different formats: digits, words and pictures. Of the 12 different mathematical problems, six were inverse and six were control problems. Half of each of these had the first element missing and half had the last element missing. Thus children completed three examples of each type of problem.

Examples of all the problems can be seen in Figure 1 (see Appendix for full list). The digit problems were presented on cards with the missing element represented by a square. The word problems were presented on cards with the problem printed below an image illustrating some aspect of the situation. All of the word problems were from the same semantic category describing 'change' situations (Carpenter \& Moser, 1982; Fuson, 1992; Riley, Greeno, \& Heller, 1983). The picture problems were presented on sets of four cards. Each card had an image of a box on it. The first card had a number on the front (a) to indicate the number of balls in the box at the outset. The second card featured a number of balls above the box with the 
legend ' $+b$ ' ( $b$ being the number of balls added). The third card featured a number of balls above the box with the legend '-c' (c being the number of balls removed). The final card was similar to the first with a number on the box (d) to indicate the number of balls in the box at the end. In each problem either the first or last number was missing and was replaced by a question mark.

\section{Procedure}

The inverse and control problems were presented to children individually in two sessions. The problems were randomly allocated to two sessions with the following restrictions: there should be equal numbers of inverse and control problems in each set; there should be equal numbers of problems with the first and last element missing in each set; there should be equal numbers of digit, word and picture problems in each set. The order in which the two sessions were completed was counterbalanced across participants.

The task was introduced as a numbers game and practice trials were given to the children to introduce the different problem types. In the digit problems children were asked to work out what number should go in the box so that the sum was correct. The question was presented and read aloud twice by the experimenter before the child responded. In the word problems children were asked to work out the amount asked in the question. The question was presented and read aloud twice by the experimenter before the child responded.

In the picture problems the experimenter placed the four cards on the table and pointed to the first card and said "Imagine there is a box with some balls in it. There are 'a' balls in it" (or "We don't know how many balls are in it" if the problem had the first element missing). The experimenter pointed at the second card and said "Some more balls are added to the box, 'b' more balls are added". The experimenter 
pointed at the third card and said "Some balls are taken out of the box, 'c' balls are taken out". The experimenter pointed at the fourth card and said "How many balls are in the box now?" (or "There are 'd' balls in the box now. How many were there to start with?" as appropriate). The cards were left on the table in a row from left to right and the experimenter repeated the description of the events and the question. No feedback was given but positive encouragement was given throughout. Participants' verbal responses were recorded.

A final session was conducted with all of the participants in their whole class at the same time. In this session a test of general arithmetic reasoning was administered - the Mathematics Assessment for Key Stage 2 (Bryant \& Nunes, 2004). Each child was given an answer booklet with an image representing each of the questions and the experimenter read the question aloud. Children were given a minute to answer each question (or until all the children signalled that they had answered the question) before the next question was read aloud. The reasoning test included 17 questions relating both to additive and to multiplicative reasoning.

\section{Results}

The measure of performance was how many of each type of problem children answered correctly. Analyses are reported below to address two main questions: 1) Are there subgroups of children with different relationships between use of the inverse principle and arithmetical skill? 2) How do the different problems factors (presentation format, identity of missing element) impact on children's performance?

The mean proportion of correct responses for the whole sample on the inversion test can be found in Table 1 . The means show that performance was higher for inverse than for control problems, which suggests that at least some children are able to use the inverse principle. The location of the missing element appears to have 
some effect on performance. The standard deviations are large in comparison to the means, indicating wide variance in the performance of participants. This may suggest that there were different subgroups with different levels of performance. Cluster analysis was used to look for subgroups within the sample.

\section{Cluster analysis}

A cluster analysis was carried out in order to look for any evidence of separate subgroups of children with different levels of use of inversion and general arithmetic performance. An hierarchical cluster analysis was performed using Ward's clustering algorithm (SPSS, version 12.0). The variables included were the standardised scores for inverse problems, control problems and the arithmetic test.

A clear three-cluster solution, which accounted for $68.8 \%$ of the variance in scores, emerged. The mean standardised score for each of the input measures for the three subgroups is given in Figure 2. There are differences in the pattern of scores by participants in each subgroup. Approximately one third of the sample were in each of the clusters. The first group $(n=21)$ tended to have high scores on the inverse problems, the control problems and the arithmetic test: thus this group included children with generally high ability. The second group $(n=22)$ tended to have low scores on all three measures: so this group included children with generally lower ability. The third group $(n=18)$ tended to have high scores on the inverse problems, but low scores on the control problems and the arithmetic test: this group therefore had high understanding of the inverse principle but poorer computation skills.

This analysis demonstrates that there are differences in the relationship between computation skills and conceptual understanding of the inverse principle among the groups. The high ability group and low ability group both show conceptual understanding that is equivalent to their computation skill. The 'inverse' group, 
however, have more advanced conceptual understanding than computation skills.

\section{Comparison of problem conditions}

The effects of the different presentation formats and problem types can now be examined. Given the existence of different subgroups within the data, this analysis will be carried out for the subgroups separately. For each group an ANOVA was conducted with three repeated-measures factors. The three factors were presentation format (digit, word, card), problem type (inverse, control) and missing element (first, last). The effects of these factors for each of the subgroups are illustrated in Figure 3.

Cluster 1 - 'high ability'. For this group of participants there were main effects of problem type $\left(F(1,20)=226.651, p<0.001, \eta_{\mathrm{p}}{ }^{2}=0.919\right)$, missing element $\left(F(1,20)=71.972, p<0.001, \eta_{\mathrm{p}}^{2}=0.783\right)$, and presentation $(F(2,19)=5.166, p=$ $\left.0.016, \eta_{\mathrm{p}}{ }^{2}=0.352\right)$. Performance was higher for inverse problems $($ mean $=0.9259)$ than for control problems $($ mean $=0.5159)$ and higher for problems with the last element missing $($ mean $=0.8757)$ than for problems with the first element missing $($ mean $=0.5661)$. Post hoc comparisons with a Bonferroni correction revealed that the difference in presentation was due to performance being higher with picture presentation $($ mean $=0.7659)$ than for word presentation $($ mean $=0.6587 ; p=0.012)$.

These main effects were qualified by an interaction between presentation format and missing element $\left(F(2,19)=4.787, p=0.021, \eta_{\mathrm{p}}{ }^{2}=0.335\right)$ and a threeway interaction between presentation format, missing element and problem type $(F(2$, 19) $=4.392, p=0.027, \eta_{\mathrm{p}}{ }^{2}=0.316$ ). Performance for problems with the first element missing $\left(F(2,19)=7.635, p=0.004, \eta_{\mathrm{p}}^{2}=0.446\right)$ was higher for picture presentation $($ mean $=0.6429)$ than for word presentation $($ mean $=0.452 ; p=0.002)$, but there was no effect of presentation on problems with the last element missing $(F<1)$. The threeway interaction revealed that the effect of missing element was not consistent across 
all problem types. There was no effect of missing element for inverse problems with digit presentation $(F(1,20)=3.216$, n.s. $)$ or picture presentation $(F(1,20)=2.105$, n.s.). However for inverse problems with word presentation $(F(1,20)=6.809, p=$ $\left.0.017, \eta_{\mathrm{p}}{ }^{2}=0.254\right)$ and control problems with all presentation formats (digit $F(1,20)$ $=24.945, p<0.001, \eta_{\mathrm{p}}^{2}=0.555 ;$ word $F(1,20)=93.077, p<0.001, \eta_{\mathrm{p}}{ }^{2}=0.823$; picture $\left.F(1,20)=17.234, p<0.001, \eta_{\mathrm{p}}{ }^{2}=0.463\right)$ performance was higher for problems with the last element missing than with the first element missing.

These effects can be demonstrated by considering the performance of one child who is typical of the group:

Hannah was in the high ability cluster. She did well with the inverse problems, answering them all correctly except for one (out of 18) which was a word problem with the first element missing. For the control problems her performance was very good with problems that had the last element missing, of which she correctly answered all except one. However she correctly answered only one of the control problems with the first element missing: this was with digit presentation.

Cluster 2 - 'low ability'. For this group of participants there were main effects of problem type $\left(F(1,21)=22.712, p<0.001, \eta_{\mathrm{p}}{ }^{2}=0.520\right)$ and missing element $\left(F(1,21)=88.953, p<0.001, \eta_{\mathrm{p}}^{2}=0.809\right)$. Performance was higher for inverse problems $($ mean $=0.3889)$ than for control problems $($ mean $=0.2096)$ and higher for problems with the last element missing $($ mean $=0.5505)$ than problems with the first element missing $($ mean $=0.0480)$. For this group there was no overall effect of presentation format. As an example:

Jack was in the low ability cluster. He struggled with many of the problems, especially those with the first element missing, of which he only answered one 
correctly (out of 18) and this was for an inverse problem presented with pictures. For the problems with the last element missing he did somewhat better for inverse problems (5 correct out of 9) compared to control problems (1 correct out of 9).

Cluster 3 - 'inverse group'. For this group of participants there were main effects of problem type $\left(F(1,17)=394.432, p<0.001, \eta_{\mathrm{p}}{ }^{2}=0.959\right)$, missing element $\left(F(1,17)=66.303, p<0.001, \eta_{\mathrm{p}}{ }^{2}=0.796\right)$ and presentation format $(F(2,16)=$ $\left.12.086, p=0.01, \eta_{\mathrm{p}}{ }^{2}=0.602\right)$. Performance was higher for inverse problems (mean $=$ $0.8395)$ than for control problems (mean $=0.2222)$ and higher for problems with the last element missing $($ mean $=0.6852)$ than for problems with the first element missing $($ mean $=0.3765)$. Post-hoc comparisons with a Bonferroni correction revealed that the difference in presentation was due to higher performance with picture presentation $($ mean $=0.5972)$ than digit presentation $($ mean $=0.5231 ; p=0.027)$ or word presentation $($ mean $=0.4722 ; p=0.001)$.

These main effects were qualified by a significant three-way interaction between presentation format, missing element and problem type $(F(2,16)=4.746, p$ $\left.=0.024, \eta_{\mathrm{p}}{ }^{2}=0.372\right)$. The effect of missing element was not consistent across all problem types. There was no effect of missing element for inverse problems with digit $(F(1,17)=1.889$, n.s. $)$ or picture presentation $(F(1,17)=3.857$, n.s. $)$. However for inverse problems with word presentation $\left(F(1,17)=34.000, p<0.001, \eta_{\mathrm{p}}{ }^{2}=0.667\right)$ and control problems with all presentation formats (digit $F(1,17)=65.642, p<0.001$, $\eta_{\mathrm{p}}^{2}=0.794 ;$ word $F(1,17)=25.500, p<0.001, \eta_{\mathrm{p}}^{2}=0.600$; picture $F(1,17)=$ 12.072, $\left.p=0.003, \eta_{\mathrm{p}}{ }^{2}=0.415\right)$ performance was higher for problems with the last element missing than for problems with the first element missing.

These effects can be demonstrated by considering one child's performance: 
Tara was in the inverse cluster. She did very well for the inverse problems, answering them all correctly except for one (out of 18) which was a word problem with the first element missing. In contrast she struggled with most of the control problems, getting none correct with digit or word presentation and only 2 correct with picture presentation (one with the first element missing and one with the last element missing).

\section{Summary}

The ANOVA comparisons demonstrated several clear effects. Participants in all three clusters performed better with inverse problems than with control problems. This indicates that children, including those in the low ability group, were able to make use of the inverse principle to solve problems. The inverse problems all included a repeated number (e.g. ? $+9-9=26 ; 17+11-11=?)$ and could have been solved correctly by children simply responding with the unrepeated number. This strategy would lead to higher accuracy on the inverse than control problems for spurious reasons. In order to identify whether children were responding on the basis of this pattern, a subset of the control problems also included a repeated number (e.g. $11+11-7=$ ?). If children were using this response strategy it would lead to characteristic errors on these control problems. Examination of children's errors revealed that there was a very low level of these particular errors (1.23\%) and no child made this error consistently. So we can be confident that the higher level of accuracy for inverse problems compared to control problems reflects children's use of a conceptually-based shortcut and not a superficial response strategy.

On the whole, problems with the first element missing were more difficult than problems with the last element missing. However this was not the case for inverse problems with picture and digit format which children in the high ability and 
inverse group were able to solve as well with the first element missing as the last element missing. Thus, when children have an advanced understanding of the inverse principle and the presentation format supports their understanding, most of them can apply this principle whether the first or the last element is missing. A wider range of problems with any of the four elements missing would allow further investigation of how flexible children can be in the way they apply their understanding of inversion.

The type of problem format affected the children's ability to solve problems. They did better with problems that were presented with pictures. This was a general effect for the inverse group. In the high ability group, however, picture presentation improved performance for problems with the first element missing only. It appears that using pictures to present problems helped to make the mathematical situation clearer to children and this effect was particularly strong for problems that children found difficult. Thus the use of pictures to present problems may be a more sensitive way of assessing children's arithmetic ability and understanding of inversion.

It appears that children may show different relationships between their understanding of inversion and their general calculation skills. The existence of the 'inverse group' indicates that at times during development at least some children can show conceptual knowledge that is more advanced than their calculation skills. Further questions remain about the different groups that were found in this experiment. Will similar groupings be found using a second sample of children from a different school? Do younger children show similar differences in the relationship between conceptual understanding and calculation skill?

\section{Experiment 2}

A second experiment was carried out to answer questions arising from experiment one. Two age groups of children were used, a different sample of Year 4 
children and a sample of younger children in Year 2. This allows investigation of how reliable the different subgroups may be and how they change with development. All the problems were presented in picture format as this had been found to be the most sensitive measure of children's performance. This was also the most appropriate presentation format to use with younger children who are not yet experienced with problems presented in formal digit format and who may have reading difficulties with the word problems. Problems were presented in the full range of missing element conditions with any one of the four elements missing. This extends the findings of experiment one to show if children can apply their understanding of inversion flexibly to this wide range of situations.

\section{Method}

\section{Participants}

Fifty-nine participants (28 females and 31 males) took part in the study. The children were from two different years groups: Year $2(n=30$, mean age $=6 ; 7$ years $\mathrm{SD}=3.4$ months $)$ and Year $4(n=29$, mean age $=8 ; 8$ years, $\mathrm{SD}=3.2$ months $)$. All children spoke English as a first language and none were classified as having special needs.

Tasks

Children were presented with four-element inverse $(a+b-b=a)$ and control $(\mathrm{a}+\mathrm{b}-\mathrm{c}=\mathrm{d})$ problems. They were given 24 problems, all of which were presented using pictures. Six problems had the first element missing, six had the second element missing, six had the third element missing and six had the final element (answer) missing. Half of each type consisted of inverse problems and half of control problems. Thus the children completed three examples of each type of problem. 
Each problem was presented using a set of four cards depicting a sequence of events concerning balls added to and removed from a box. Each card had an image of a box on it. The first card had a number on the front (a) to indicate the number of balls in the box at the outset. The second card featured a number of balls above the box with the legend ' $+b$ ' ( $b$ being the number of balls added). The third card featured $a$ number of balls above the box with the legend '-c' (c being the number of balls removed). The final card was similar to the first with a number on the box (d) to indicate the number of balls in the box at the end. In each problem one of the elements (a, b, c or d) was missing and was replaced by a question mark and if necessary the image of the balls was obscured so that they could not be counted. Examples of all the problems can be seen in Figure 4 (see Appendix for full list).

Different sets of problems were used for each age group which were chosen so that the control problems would be difficult for children to solve, but not so difficult that they would deter children from attempting a solution. Children with a good understanding of inversion should be able to apply this principle regardless of the size of the problems. However, performance in the control problems would have been at ceiling for the Year 4 group or at floor for the Year 2 group if the same sets of problems had been used for both year groups. The problems with element one and element four missing were the same for the Year 4 group as the picture problems used in experiment one.

\section{Procedure}

Each participant was tested individually in three sessions. The inverse and control picture problems were presented to children across two sessions. The problems were randomly allocated to two sessions with the restriction that there 
should be equal numbers of inverse and control problems in each set. The order in which the two sessions were completed was counterbalanced across participants.

The task was introduced as a numbers game and the scenario with balls added to and removed from a box was explained to participants. The problems were presented using only the cards rather than also presenting concrete materials because a pilot study had revealed no difference in performance by young children whether the items were presented with cards only or cards and concrete materials. At the beginning of each session there were three practice trials with simple control problems. For each trial the experimenter placed the first card on the table and said "Imagine there is a box with some balls in it. There are 'a' balls in it" (or "We don't know how many balls are in it" if the problem had the first element missing). The second card was then placed on the table and the experimenter said "Some more balls are added to the box, 'b' more balls are added" (or "We don't know how many balls are added"). The third card was then placed onto the table and the experimenter said "Some balls are taken out of the box, 'c' balls are taken out" (or "We don't know how many balls are taken out"). The fourth card was then placed on the table and the experimenter said "How many balls are in the box now?" (or "There are 'd' balls in the box now. How many were added / taken out / there to start with?" as appropriate). The cards were left on the table in a row from left to right and the experimenter repeated the description of the events and the question. No feedback was given but positive encouragement was given throughout. The participants' verbal responses were recorded.

A final session was conducted with each participant individually. In this session the Wechsler Objective Numerical Dimension (WOND) test was administered (Wechsler, 1996). This test consists of two subtests: mathematical reasoning and 
numerical operations. The mathematical reasoning subtest assesses children's understanding of the number system, knowledge of shapes, measurement, time, money, use of charts, simple mental arithmetic, place value and fractions. The numerical operations subtest assesses children's skill at solving a set of simple written addition, subtraction, multiplication and division problems. The test involves a wide range of activities and was included to obtain a standardized measure of children's general maths achievement.

\section{Results}

The measure of performance was how many of each type of problem children answered correctly. As before, the first question to be addressed using cluster analysis was whether there are different subgroups in the sample and if these are similar for the two year groups. Following this the effect of different problem factors on performance was investigated using ANOVA.

The mean proportion of correct responses for the inversion test can be found in Table 2. The means show that performance was higher for inverse than control problems. The location of the missing element appears to have some effect on performance.

\section{Cluster analysis}

Cluster analyses were carried out for each year group separately to determine whether there was evidence of separate subgroups and if these were similar for the different age groups. The variables included were standardised scores on inverse problems, control problems and the WOND. Hierarchical cluster analyses were performed using Ward's clustering algorithm and both revealed a clear three-cluster solution which accounted for $70.2 \%$ of the variance in Year 4 scores and $59.2 \%$ of the 
variance in Year 2 scores. The mean standardised score on each of the input measures for the three subgroups is given in Figure 5.

The cluster analyses revealed three subgroups, as in experiment one. These groups have generally similar characteristics across the two age groups which match the pattern found in experiment one. In each year group the first cluster was a 'high ability' cluster consisting of children who scored high on the inverse problems, the control problems and the WOND test. In both year groups this was a small cluster consisting of only 6 children in Year 2 and 7 children in Year 4. The next cluster was a 'low ability' cluster consisting of children who scored low on the inverse problems, the control problems and the WOND test. In Year 2 this was the largest cluster consisting of 18 children, in Year 4 this is the smallest cluster consisting of only 4 children.

The characteristics of the third cluster were slightly different in the two year groups. In Year 2 this cluster consisted of 6 children who scored high on the inverse problems and WOND test but low on the control problems. In Year 4 this was the largest cluster consisting of 17 children who scored high on the inverse problems but low on the control problems and WOND test. Thus the third cluster for the Year 4 group was similar to that found in experiment one. These children had good inverse understanding, which is more advanced than their calculation skills and general arithmetic abilities. However in the Year 2 group the third cluster had slightly different characteristics. These children had generally good arithmetic reasoning abilities, which was not restricted to their understanding of the inverse principle. These abilities still outstripped their calculation skills as shown by poor performance on the control problems. This contrast may be due to characteristics of the WOND test. The early questions concerned maths reasoning while later questions involved 
more calculation. Thus for the younger children the WOND may have tended to test arithmetic reasoning whilst for older children it may have tested arithmetic calculation skills. This may account for the slight differences in profile of performance for the inverse group in Year 2 and Year 4. The WOND test was not included as an a priori measure of either conceptual understanding or calculation skill but rather to discover how children's performance on the inverse and control problems may have related to more general maths achievement.

The cluster analysis suggests that scores on this test may have tended to reflect calculation skills in the older children, however it does include a wide range of activities and is not a pure test of either calculation skill or conceptual understanding.

\section{Comparison of problem conditions}

As there is evidence of separate subgroups within the sample, the effects of different problem types should be examined for each group separately. Children's performance on inverse and control problems was compared to determine if children are able to make use of the inverse principle. The effect of where the missing element is on children's inversion use was investigated to reveal how flexibly they can apply their conceptual understanding. Where group sizes allow, ANOVA was used to test these factors.

Year 2. The performance of participants in each cluster is shown in Figure 6. The largest cluster in this year was the low ability cluster $(n=18)$. The high ability cluster and inverse cluster were both smaller $(n=6)$. The figure reveals that children in all three groups gave more accurate responses for the inverse problems than control problems. The low ability cluster was large enough to allow statistical comparison and performance was significantly better on inverse than control problems $(F(1,17)=$ 29.877, $\left.p<0.001, \eta_{\mathrm{p}}{ }^{2}=0.637\right)$. This suggests that even the children in the low ability 
cluster of the younger age group have some understanding of the inverse principle and can use it to solve problems.

Figure 6 also reveals the effect of the missing element on performance by children in each cluster. For the low ability cluster it appears that there was no effect of the identity of the missing element for either inverse problems or control problems and statistical comparison confirms this $(F(3,15)=1.356$, n.s. $)$. This suggests that while children in this cluster were only able to apply the inverse principle on about one third of the problems that it is relevant, they can do so flexibly regardless of the identity of the missing element. The lack of effect of missing element on control problems may be because performance is so low.

For children in the high ability cluster the missing element did not appear to have any effects on performance on inverse problems indicating that these children had good understanding of the inverse principle which they could apply flexibly to all relevant situations. The identity of the missing element did appear to have an effect on control problems with performance higher for canonical problems with the answer missing than for problems with any of the other elements missing.

For children in the inverse cluster there was no effect of missing element on control problems due to floor effects. For inverse problems performance was lower for problems with element 2 missing rather than any other element. This is a surprising result since previous work has suggested that problems with element 1 missing are the most difficult to solve (Abnett \& Bryant, 2004), however this is only a small group.

Year 4. The effect of different problem types can also be examined for the different subgroups in Year 4 as shown in Figure 7. The largest cluster in this year is the inverse cluster $(n=17)$ with smaller high ability $(n=7)$ and low ability $(n=4)$ 
clusters. There was a clear inverse effect for the inverse cluster which can be confirmed by statistical analysis $\left(F(1,16)=365.414, p<0.001, \eta_{\mathrm{p}}{ }^{2}=0.958\right)$. Children in the low ability cluster performed only slightly better on inverse than control problems suggesting that this small group may include children who do not have a clear understanding of the inverse principle. However performance is so low overall that it is difficult to draw strong conclusions for this group. Children in the high ability cluster also showed an inverse effect, although performance was so high for control problems with elements 3 and 4 missing that performance for inverse problems is only slightly higher.

The identity of the missing element also appeared to have some impact on children's performance. For the inverse cluster there was an interaction between missing element and problem type $\left(F(3,14)=8.008, p=0.002, \eta_{\mathrm{p}}{ }^{2}=0.632\right)$ with an effect of missing element for the control problems $\left(F(3,14)=15.892, p<0.001, \eta_{\mathrm{p}}{ }^{2}\right.$ $=0.773)$ but not for inverse problems $(F(3,14)=1.726$, n.s. $)$, so these children could apply the inverse principle flexibly whichever element is missing. For control problems performance was higher for canonical problems (element 4 missing) than for non-canonical problems (element 3 missing $p=0.015$; element 2 missing $p=$ 0.004; element 1 missing $p<0.001$ with Bonferroni correction). For the low ability cluster performance was low overall but appeared to be somewhat higher for canonical problems than non-canonical problems. For the high ability cluster the effect of the missing element appears to be different for inverse and control problems. For inverse problems performance was higher for problems with element 3 or element 4 missing than for problems with element 1 or element 2 missing. For control problems there appears to be a trend with performance lower if the missing element is towards the beginning of the sum. 


\section{Summary}

The results indicate that similar subgroups have been found showing children with different relationships between conceptual knowledge and calculation skill. While some children show conceptual knowledge that is in line with their calculation skill, others show conceptual knowledge that is more advanced than would be expected from their general arithmetic performance. These two alternative relationships have been found for children in the younger as well as older age group. The comparison of problem factors reveal that use of the inverse principle was widespread. Even children in the low ability group of the younger age group performed better on inverse than control problems. Children can generally apply the inverse principle flexibly across problems regardless of which element is missing. As with experiment one, children's errors were examined to ensure that they were not using a superficial response strategy of answering the inverse problems by saying the unrepeated number. This strategy would lead to correct answers on inverse problems, but also to characteristic errors on a subset of control problems which also included a repeated number (e.g. $16+16-?=24 ; 11+11-7=$ ?). Examination of the responses to this set of problems revealed that there was a very low level of these characteristic errors $(0.85 \%)$ and no child made this error consistently. Therefore children's higher level of accuracy on the inverse problems is not due to them responding purely on the basis of the pattern of numbers within the problem.

\section{General Discussion}

The two experiments reported here provide clear evidence of children's flexible use of the inverse principle and reveal the importance of investigating individual differences when considering children's conceptual understanding of arithmetic. These findings have important implications for mathematics education. 
In both experiments children consistently solved more inverse problems than matched control problems, which indicates that they could understand the inverse relationship between addition and subtraction and use this knowledge to solve problems. Even children in the low ability cluster of the younger year group showed an inverse effect. The inverse effect was not due to children responding to the distinctive pattern of numbers within the problem, but rather to a selective application of the inverse principle only to the problems where it was relevant. Evidently children grasp at least some understanding of the inverse principle early in the development of their arithmetic expertise. This is an important underlying principle that provides the basis for children to develop concepts including additive composition and to make use of strategies such as decomposition.

Previous studies have found mixed results concerning the relationship between children's understanding of inversion and their arithmetical skills with some evidence of a developmental trend (Bryant et al., 1999; Klein \& Bisanz, 2000; Rasmussen et al., 2003; Stern, 1992). In these cases the sample has been considered as a single group. However the present experiments reveal the importance of considering individual differences in the nature of this relationship. By grouping children who show more similar profiles of performance we can begin to make sense of these wide differences and draw some general conclusions about the range of different performance profiles observed.

Three clear groups were found representing different profiles of achievement on tests of inverse knowledge and arithmetical skill. This pattern was replicated across two different samples of children in Year 4 and also for a sample of children in Year 2. So there appear to be reliable subgroups of children with distinct patterns of performance. One group showed good conceptual understanding and high arithmetical 
skill, the second group showed poorer conceptual understanding in line with their lower arithmetical skill. The final group showed good conceptual understanding whilst scoring poorly on measures of arithmetical skill. Thus the majority of children show a relationship between their conceptual understanding and calculation skills whether these are at a high or lower level. However a substantial subgroup of children exists, whose conceptual understanding far outstrips their arithmetical skill. The presence of these three distinct subgroups show how important it is to consider individual differences in children's arithmetic performance. In many cases year group means may not be representative of the performance of any children in the group. Three distinct subgroups were found in both the older and younger age groups but the proportion of children in each group was somewhat different. For the younger children the 'low ability' group was the largest while for the older children the groups were either equal sized or the 'inverse' group was the largest. This difference may just represent a sampling effect or the appropriateness of the difficulty of problems selected for each age group. Alternatively this could be evidence of a developmental trend. These different subgroups may reflect groupings of children who are at different points along a gradual developmental path progressing from general low ability to general high ability through first gaining increased conceptual understanding and then arithmetical skills catching up. So the proportions of children in the groups at different ages may represent development across two years with more children moving into the inverse and the high ability groups.

An alternative interpretation of these different subgroups is that they may represent different paths of development. Some children may develop conceptual understanding in advance of their arithmetical skill whilst for other children the two components develop together. It is interesting to note that there is not a fourth 
subgroup of children who show more advanced arithmetical skill than conceptual understanding. These children could use their advanced arithmetical skill to accurately solve both the inverse and the control problems to the same extent and so would not show an inverse effect. Response times would also distinguish this subgroup from the high ability group as these children would not show faster responses for inverse than control problems whilst the children with good conceptual understanding of the inverse principle would. In order to determine whether the subgroups found in the present study represent a single path of development or alternative paths of development longitudinal studies would be required. These would reveal the extent to which children move between the different subgroups as their arithmetic expertise develops.

In this study children were presented with inverse problems in a wider variety of formats than previously used which affected their performance on both inverse and control problems. The use of pictures to describe problem situations proved to be a sensitive measure, not only of children's problem solving performance but also of their conceptual understanding. This context-rich presentation format allowed children to apply their inverse knowledge flexibly regardless of which element of the problem was missing. In contrast, when problems were presented in word format children had particular difficulties in solving inverse problems with the first element missing. Thus children have a sophisticated understanding of the inverse principle that they can demonstrate when problems are presented using pictures. However the format of a problem can restrict them from identifying situations where their knowledge is relevant and successfully applying it. Given the prevalence of word problems in primary school arithmetic classes it is worrying that this appears to be a format that prevents children from making use of the conceptual knowledge they 
have. In contrast, more meaningful presentation formats such as the use of pictures, may support children in the accurate use of procedural skills as well as support the introduction of arithmetic concepts such as inverse relations.

The evidence of the existence of a subgroup of children with high conceptual understanding but poor computational skills has interesting implications for theories of children's arithmetical development and important consequences for education. These children have advanced conceptual understanding of the inverse principle compared to their poor arithmetical skill. This demonstrates that understanding of the relationship between addition and subtraction does not only develop out of proficiency with these operations. There must be alternative ways to develop understanding of this relationship.

As children can show different profiles of conceptual understanding and arithmetical skill this has wide ranging implications for education. It demonstrates the importance of looking at profiles of educational achievement rather than a single measure of performance. Both conceptual understanding and problem solving skills must be considered. If only problem-solving accuracy is considered without conceptual understanding then children in the inverse group will appear to be the same as the low ability group. They will be at risk of being misclassified as low achievers, without consideration of their advanced conceptual understanding. We need a clear picture of children's abilities to ensure they receive appropriate educational support. It is likely that children with a wide discrepancy between their conceptual understanding and calculation skill will benefit from different educational approaches to those with generally low performance across both components.

Children with advanced conceptual understanding should benefit from approaches that make use of their good conceptual knowledge as a means to help 
them discover and improve their calculation procedures. These different profiles of conceptual understanding and calculation skill also have implications for the use of setting in schools. There has been an increase over recent years in the use of ability grouping in primary schools, particularly for mathematics (Ireson \& Hallam, 2001). This raises the question of how to group children who may have widely differing abilities across different components of arithmetic (Dowker, 2004). Longitudinal studies are needed to follow the development of children with more advanced conceptual understanding than procedural skill to investigate their long-term outcomes. This will reveal whether these children are able to improve their calculation skills to match the level of their conceptual understanding or whether they continue to show an asymmetric profile of performance. 


\section{References}

Abnett, C. K., \& Bryant, P. (2004, April). Children's understanding of the arithmetic principle of inversion. Poster session presented at the British Psychological Society Annual Conference, London.

Baroody, A. J., \& Gannon, K. E. (1984). The development of the commutativity principle and economical addition strategies. Cognition and Instruction, 1, 321-339.

Bisanz, J. \& LeFevre, J. A. (1990). Strategic and nonstrategic processing in the development of mathematical cognition. In D.F. Bjorklund (Ed.) Children's strategies: Contemporary views of cognitive development. Hillsdale, NJ: Erlbaum.

Bisanz, J., LeFevre, J.A., \& Gilliland, S. (1989, April). Developmental changes in the use of logical principles in mental arithmetic. Poster session presented at the biennial meeting of the Society for Research in Child Development, Kansas City, MO.

Bryant, P., Christie, C., \& Rendu, A. (1999). Children's understanding of the relation between addition and subtraction: Inversion, identity and decomposition. Journal of Experimental Child Psychology, 74, 194-212.

Bryant, P. \& Nunes. T. (2004). The results of a new mathematical reasoning task given to a large number of 8-year old children. Manuscript in preparation.

Canobi, K. H. (2004). Individual differences in children's addition and subtraction knowledge. Cognitive Development, 19, 81-93.

Canobi, K. H., Reeve, R. A., \& Pattison, P. E. (1998). The role of conceptual understanding in children's addition problem solving. Developmental Psychology, 34(5), 882-891. 
Canobi, K. H., Reeve, R. A., \& Pattison, P. E. (2002). Young children's understanding of addition concepts. Educational Psychology, 22(5), 513-532.

Canobi, K. H., Reeve, R. A., \& Pattison, P. E. (2003). Patterns of knowledge in children's addition. Developmental Psychology, 39(3), 521-534.

Carpenter, T. P., \& Moser, J. M. (1982). The development of addition and subtraction problem-solving skills. In T. P. Carpenter, J. M. Moser \& T. A. Romberg (Eds.), Addition and subtraction: A cognitive perspective (pp. 9-24). Hillsdale, NJ: Lawrence Erlbaum Associates.

Cowan, R., \& Renton, M. (1996). Do they know what they are doing? Children's use of economical addition strategies and knowledge of commutativity. Educational Psychology, 16(4), 407-420.

Dowker, A. (2004). What works for difficulties in mathematics. London: DfES

Fuson, K. C. (1992). Research on whole number addition and subtraction. In D. A. Grouws (Ed.), Handbook for research on mathematics teaching and learning (pp. 243-275). New York: Macmillan.

Ireson, J. \& Hallam, S. (2001). Ability grouping in education. London: Paul Chapman.

Klein, J. S., \& Bisanz, J. (2000). Preschoolers doing arithmetic: The concepts are willing but the working memory is weak. Canadian Journal of Experimental Psychology, 54(2), 105-115.

Piaget, J. (1952). The child's conception of number. London: Routledge \& Kegan Paul.

Piaget, J. \& Moreau, A. (2001). The inversion of arithmetic operations. In J. Piaget (Ed)., Studies in reflecting abstraction (R.L.Campbell, Trans., pp. 69-86). Hove, UK: Psychology Press. (Original work published 1977). 
Rasmussen, C., Ho, E., \& Bisanz, J. (2003). Use of the mathematical principle of inversion in young children. Journal of Experimental Child Psychology, 85, 89-102.

Riley, M., Greeno, J. G., \& Heller, J. I. (1983). Development of children's problemsolving ability in arithmetic. In H. P. Ginsburg (Ed.), The development of mathematical thinking (pp. 153-196). New York: Academic Press.

Siegler, R.S. \& Stern, E. (1998). Conscious and unconscious strategy discoveries: A microgenetic analysis. Journal of Experimental Psychology - General, 127, 377-397.

Starkey, P., \& Gelman, R. (1982). The development of addition and subtraction abilities prior to formal schooling in arithmetic. In T. P. Carpenter, J. M. Moser, \& T. A. Romberg (Eds.), Addition and subtraction: A cognitive perspective (pp. 99-116). Hillsdale, NJ: Lawrence Erlbaum Associates.

Stern, E. (1992). Spontaneous use of conceptual mathematical knowledge in elementary school children. Contemporary Educational Psychology, 17, 266277.

Vilette, B. (2002). Do young children grasp the inverse relationship between addition and subtraction? Evidence against early arithmetic. Cognitive Development, $17,1365-1383$.

Wechsler, D. (1996). Wechsler Objective Numerical Dimensions. London: Psychological Corporation. 
Table 1

Means (and standard deviations) for the proportion of correct responses for different problem types in experiment one.

\begin{tabular}{|c|c|c|c|c|c|c|}
\hline \multirow[t]{2}{*}{ Problem } & \multicolumn{3}{|c|}{ First element missing } & \multicolumn{3}{|c|}{ Last element missing } \\
\hline & Digit & Word & Picture & Digit & Word & Picture \\
\hline \multicolumn{7}{|l|}{ Inverse } \\
\hline Mean & 0.5253 & 0.470 & 0.636 & 0.828 & 0.879 & 0.879 \\
\hline SD & 0.472 & 0.422 & 0.429 & 0.288 & 0.266 & 0.246 \\
\hline \multicolumn{7}{|l|}{ Control } \\
\hline Mean & 0.116 & 0.020 & 0.147 & 0.520 & 0.495 & 0.566 \\
\hline SD & 0.258 & 0.080 & 0.287 & 0.310 & 0.352 & 0.336 \\
\hline
\end{tabular}


Table 2

Means (and standard deviations) for the proportion of correct responses for different problem types in experiment two.

\begin{tabular}{|c|c|c|c|c|c|c|c|c|}
\hline \multirow{2}{*}{$\begin{array}{l}\text { Element } \\
\text { missing }\end{array}$} & \multicolumn{4}{|c|}{ Inverse problems } & \multicolumn{4}{|c|}{ Control problems } \\
\hline & $\overline{E 1}$ & $\overline{\mathrm{E} 2}$ & E3 & $\mathrm{E} 4$ & E1 & $\bar{E} 2$ & E3 & $\mathrm{E} 4$ \\
\hline \multicolumn{9}{|l|}{ Year 2} \\
\hline Mean & 0.522 & 0.489 & 0.633 & 0.600 & 0.044 & 0.044 & 0.100 & 0.167 \\
\hline SD & 0.408 & 0.389 & 0.404 & 0.423 & 0.115 & 0.115 & 0.155 & 0.273 \\
\hline \multicolumn{9}{|l|}{ Year4 } \\
\hline Mean & 0.770 & 0.736 & 0.851 & 0.897 & 0.092 & 0.207 & 0.402 & 0.644 \\
\hline SD & 0.346 & 0.371 & 0.303 & 0.269 & 0.152 & 0.273 & 0.371 & 0.308 \\
\hline
\end{tabular}


Figure captions

Figure 1. Example problems in digit, word and picture format used in experiment one. Figure 2. Standardised scores for inverse problems, control problems and mathematics test for each cluster from experiment one.

Figure 3. Accuracy for different problem types and presentation formats for children in a) high ability cluster, b) low ability cluster and c) inverse cluster.

Figure 4. Example inverse and control problems used in experiment two.

Figure 5. Standardised scores for inverse problems, control problems and WOND test for each cluster in a) Year 2 and b) Year 4 from experiment two.

Figure 6. Accuracy for different problem types for Year 2 children in a) high ability cluster, b) low ability cluster and c) inverse cluster.

Figure 7. Accuracy for different problem types for Year 4 children in a) high ability cluster, b) low ability cluster and c) inverse cluster. 


\begin{tabular}{|c|c|c|c|}
\hline Format & $\begin{array}{c}\text { Problem } \\
\text { type }\end{array}$ & $\begin{array}{l}\text { Missing } \\
\text { element }\end{array}$ & Example \\
\hline \multirow[t]{4}{*}{ Digit } & \multirow[t]{2}{*}{ Inverse } & First & {[]$+7-7=13$} \\
\hline & & Last & $15+12-12=[]$ \\
\hline & \multirow[t]{2}{*}{ Control } & First & {[]$+14-9=18$} \\
\hline & & Last & $11+11-7=[]$ \\
\hline \multirow[t]{4}{*}{ Word } & \multirow[t]{2}{*}{ Inverse } & First & $\begin{array}{l}\text { Daniel had some cards, he found } 7 \text { more and then lost } \\
\text { 7. At the end he had } 13 \text {. How many did he have to start } \\
\text { with? }\end{array}$ \\
\hline & & Last & $\begin{array}{l}\text { Jamie had } 15 \text { balls, he found } 12 \text { more and then lost } 12 \text {. } \\
\text { At the end, how many balls did he have? }\end{array}$ \\
\hline & \multirow[t]{2}{*}{ Control } & First & $\begin{array}{l}\text { Julia had some balls, she won } 14 \text { more and then lost } 9 . \\
\text { At the end she had } 18 \text {. How many did she have to start } \\
\text { with? }\end{array}$ \\
\hline & & Last & $\begin{array}{l}\text { Emily had } 11 \text { chocolates, she won } 11 \text { more and then } \\
\text { ate } 7 . \text { At the end, how many chocolates did she have? }\end{array}$ \\
\hline \multirow[t]{4}{*}{ Picture } & \multirow[t]{2}{*}{ Inverse } & First & 10 \\
\hline & & Last & 12 \\
\hline & \multirow[t]{2}{*}{ Control } & First & \\
\hline & & Last & $\because \because 0-7$ \\
\hline
\end{tabular}




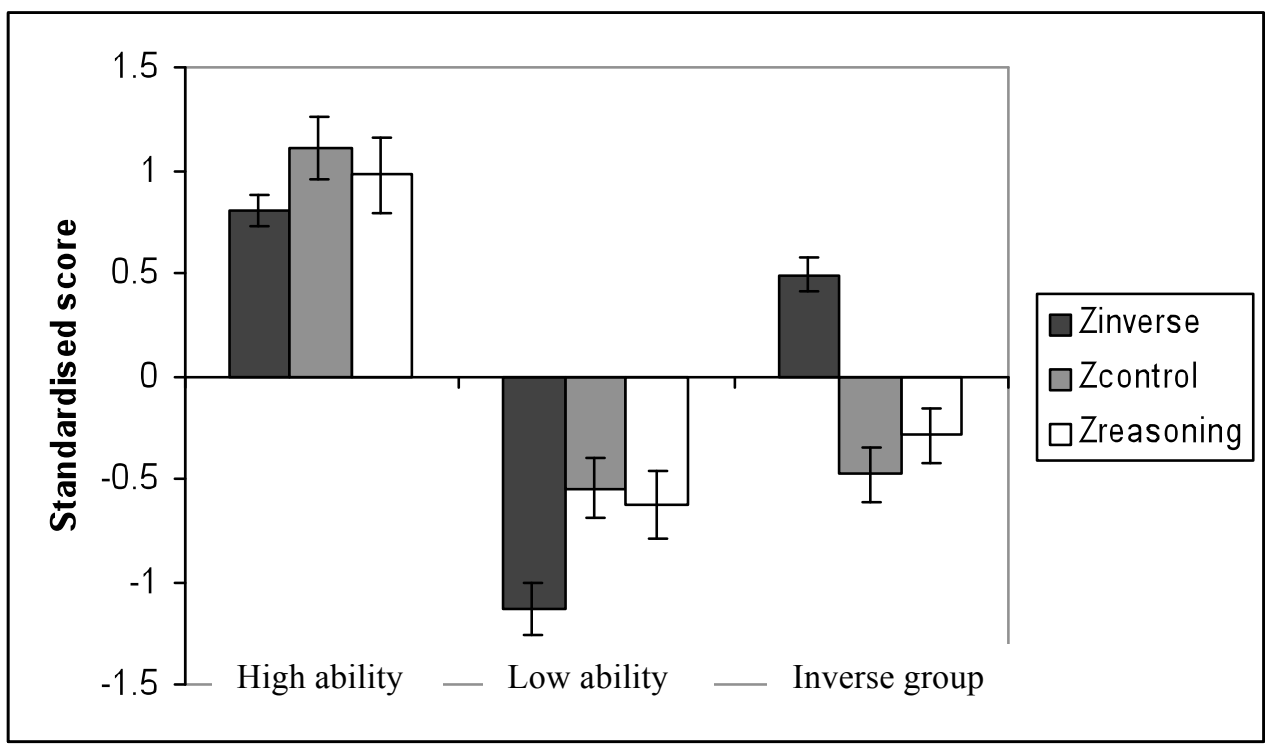


a) High ability cluster

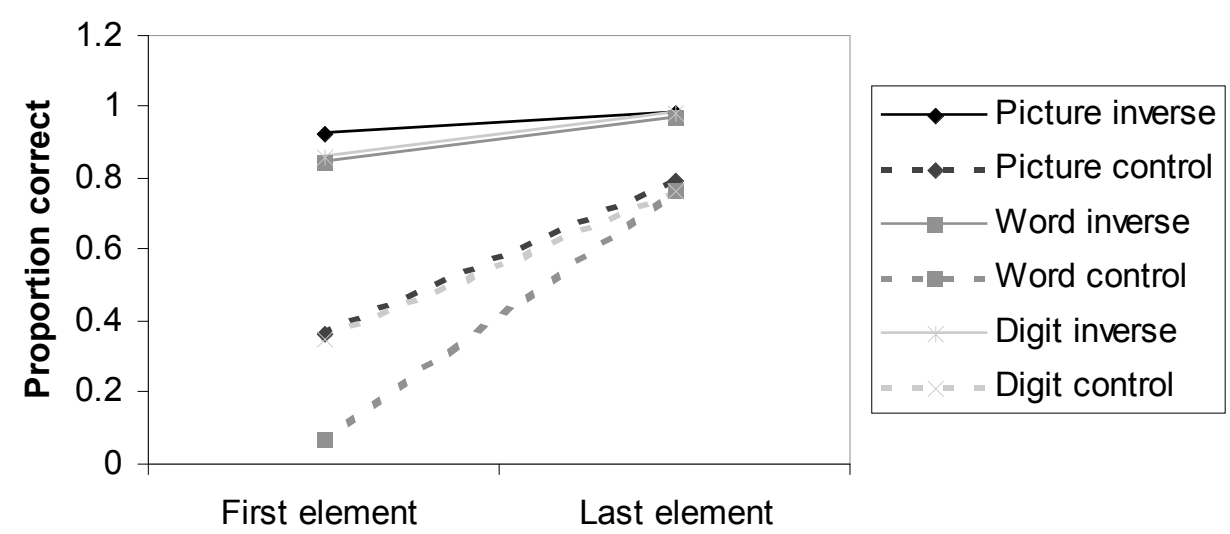

Element missing

\section{b) Low ability cluster}

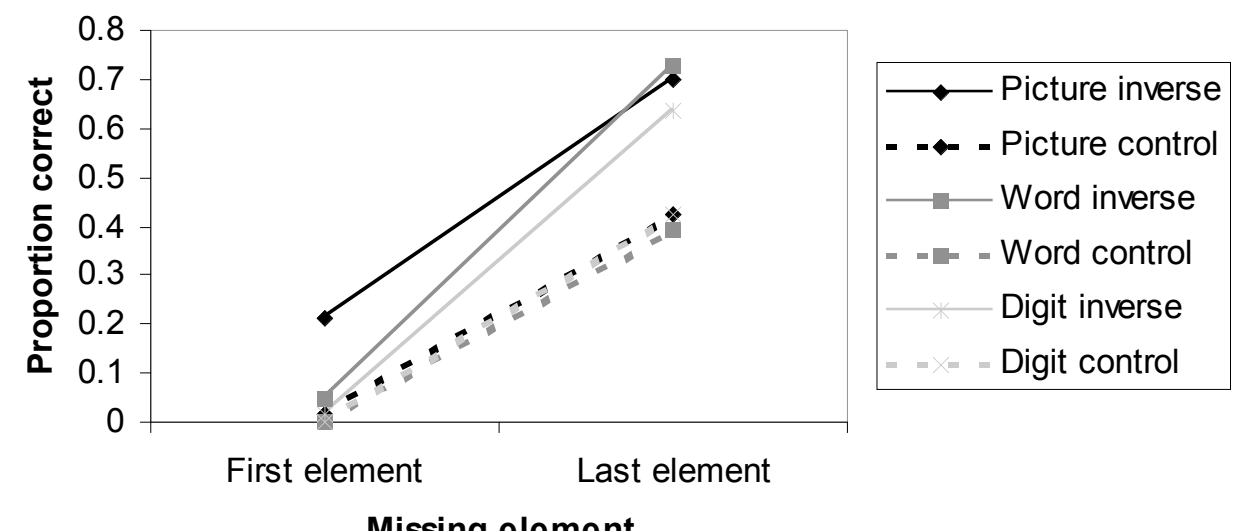

Missing element

\section{c) Inverse cluster}

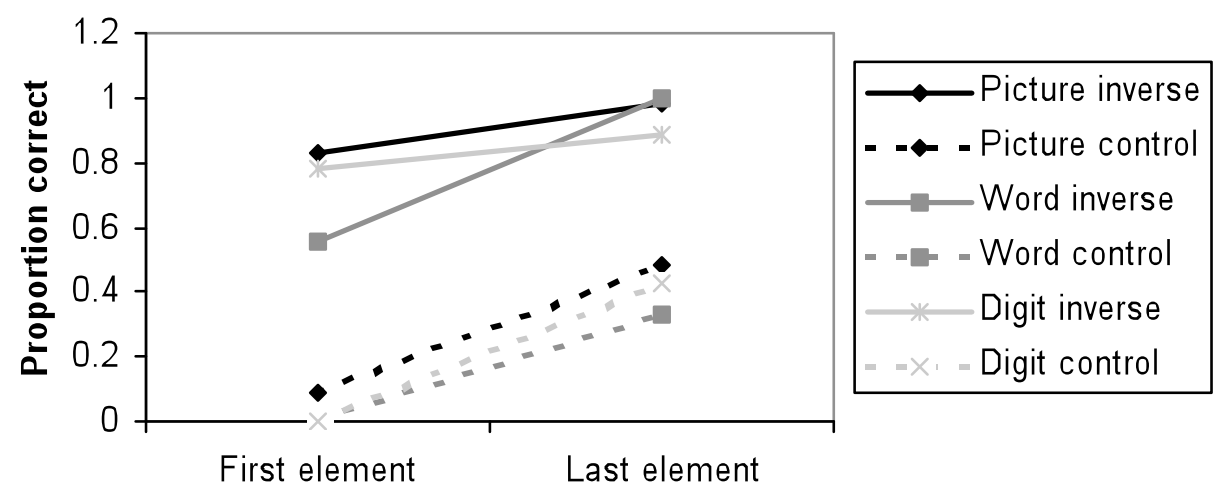

Missing element 


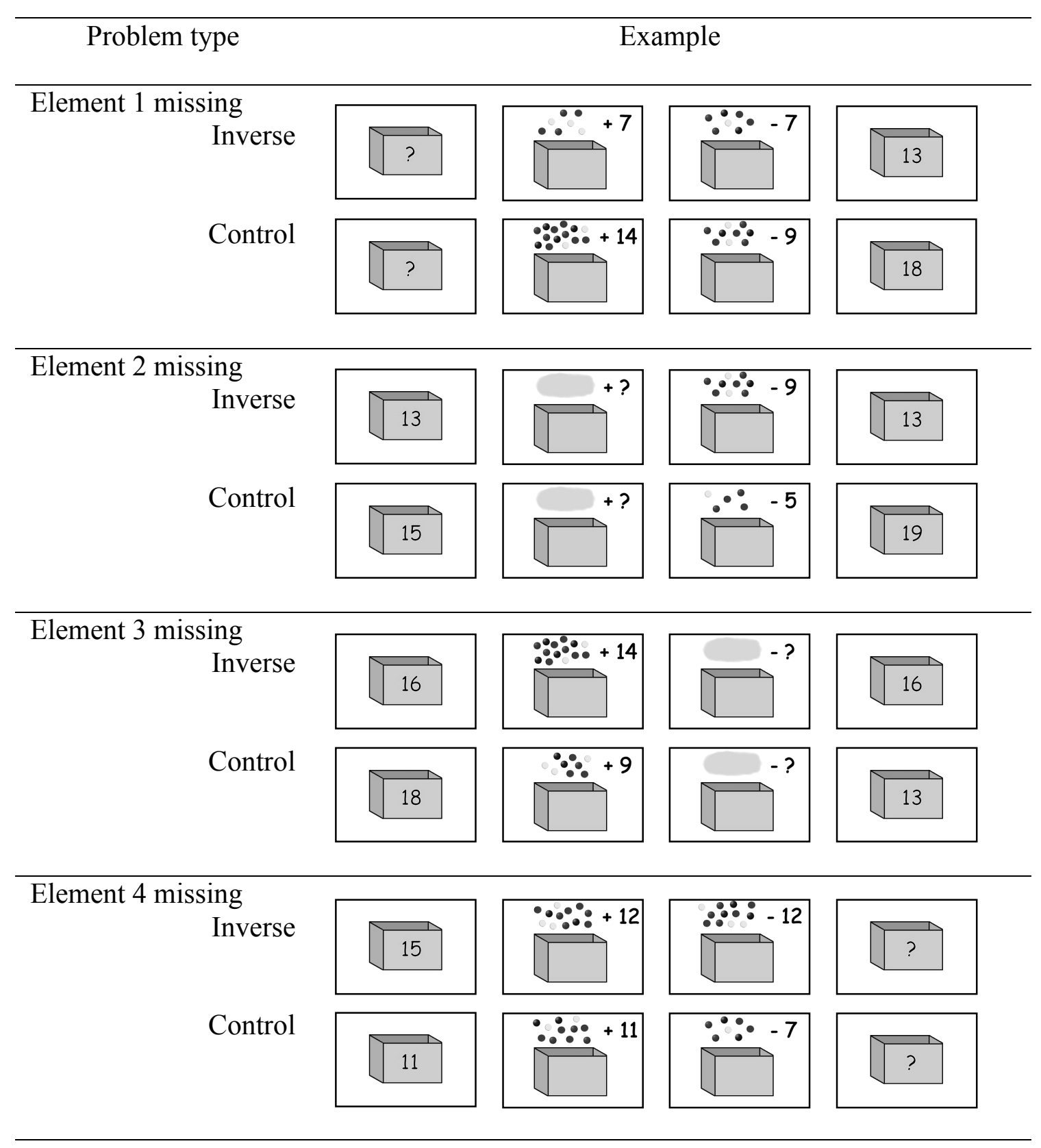


a) Year 2

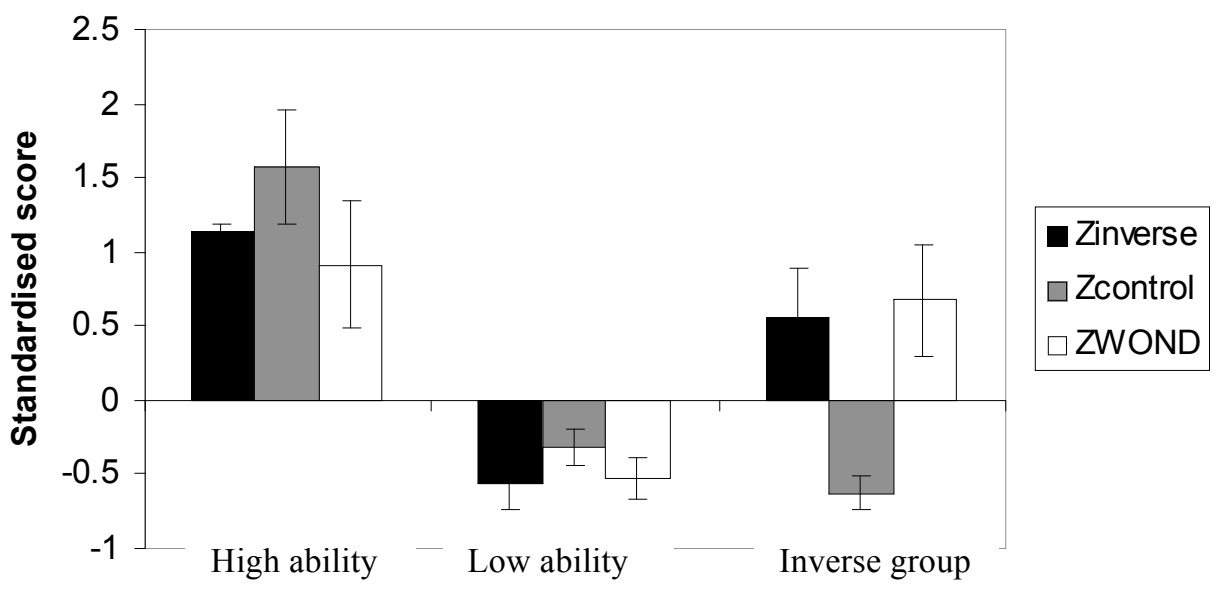

b) Year 4

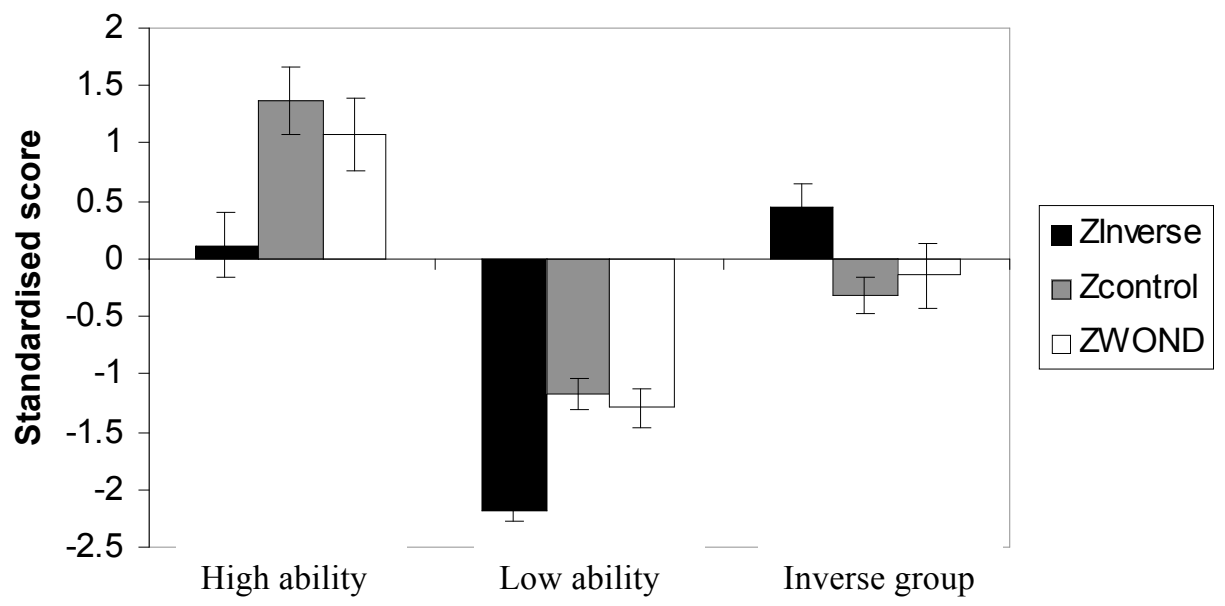


a) High ability cluster $n=6$

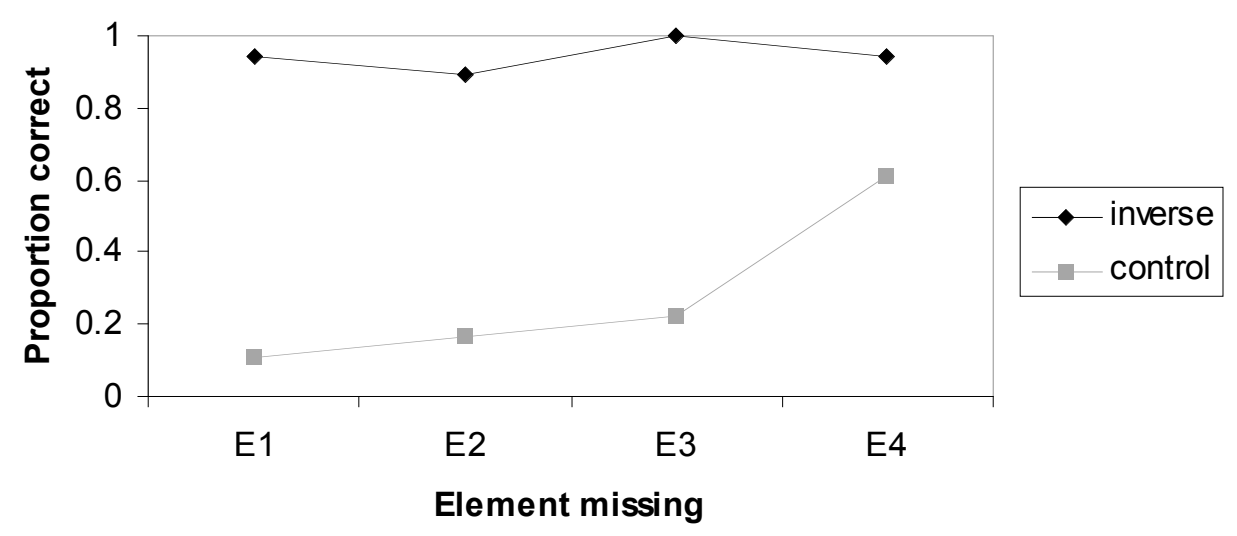

b) Low ability cluster $n=18$

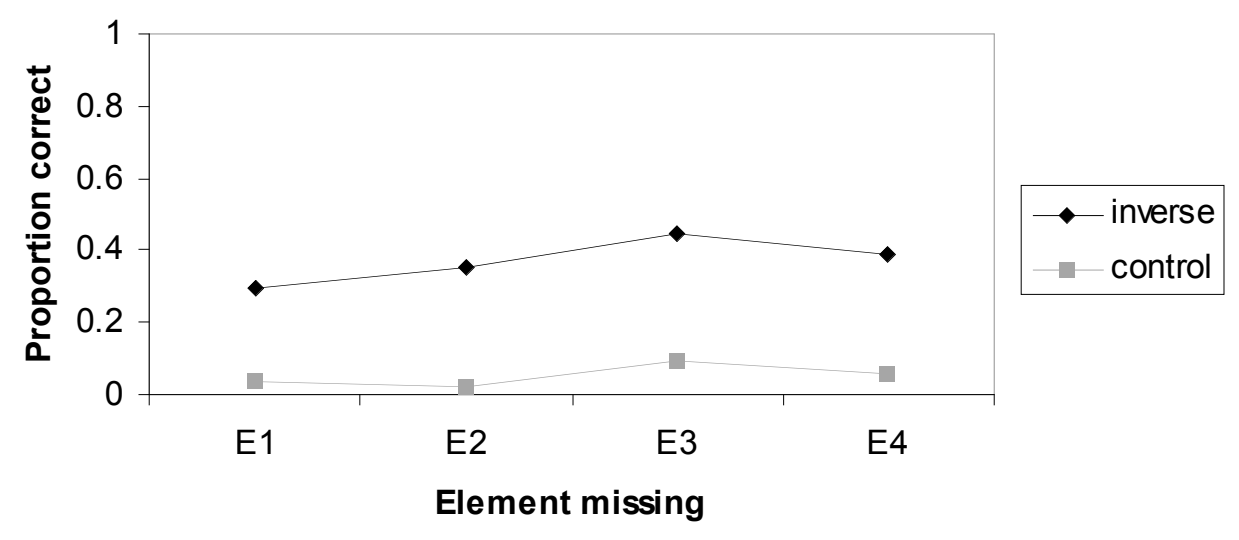

c) Inverse cluster $n=6$

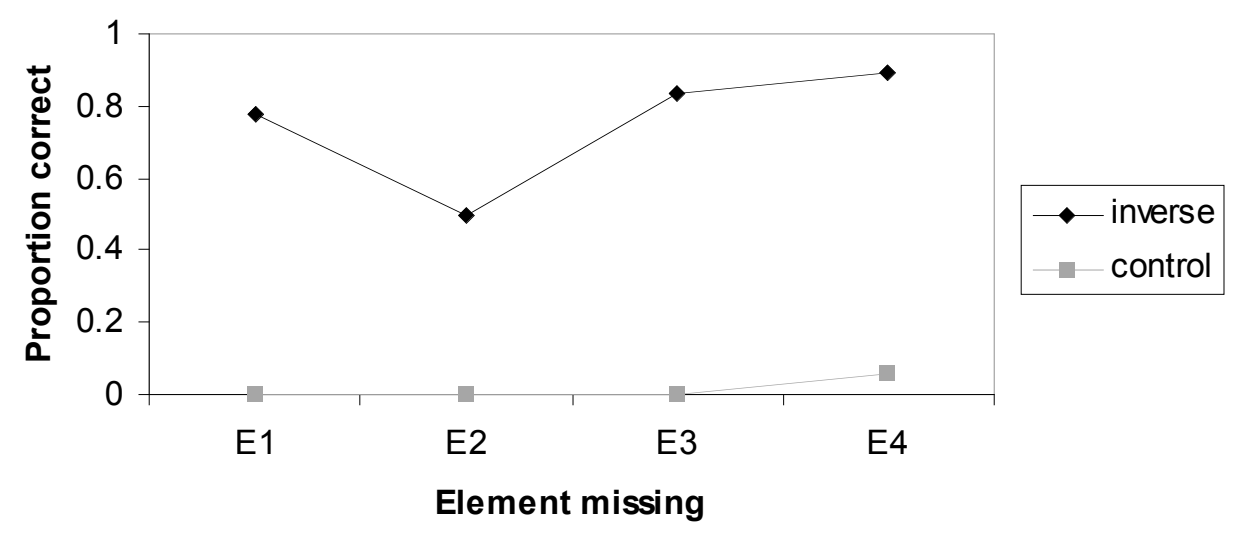


a) High ability cluster $n=7$

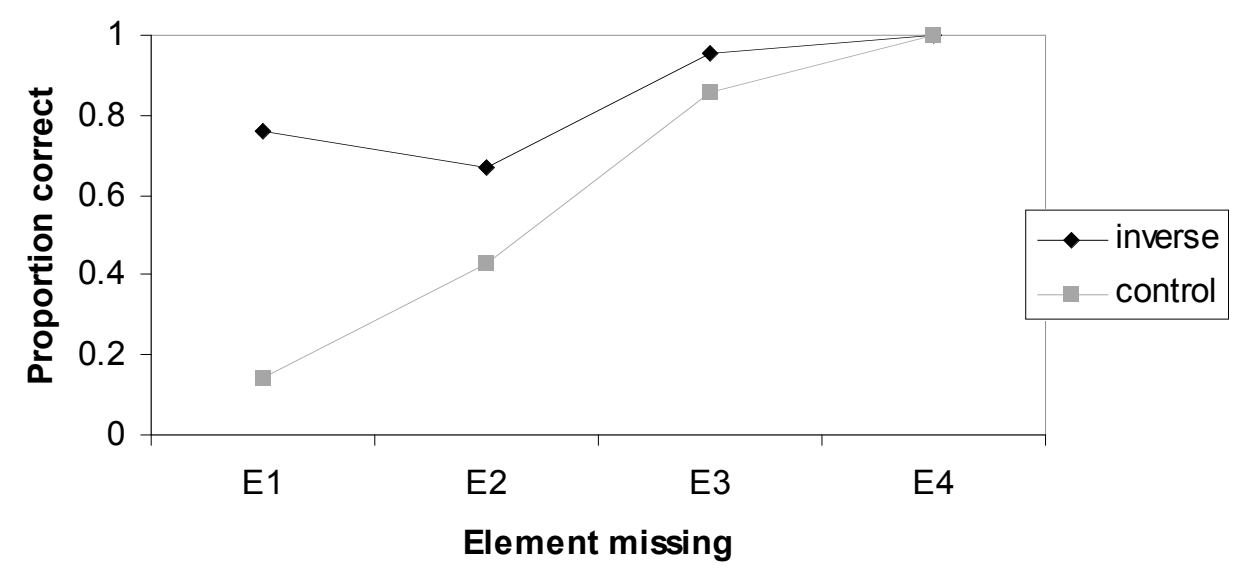

b) Low ability cluster $n=4$

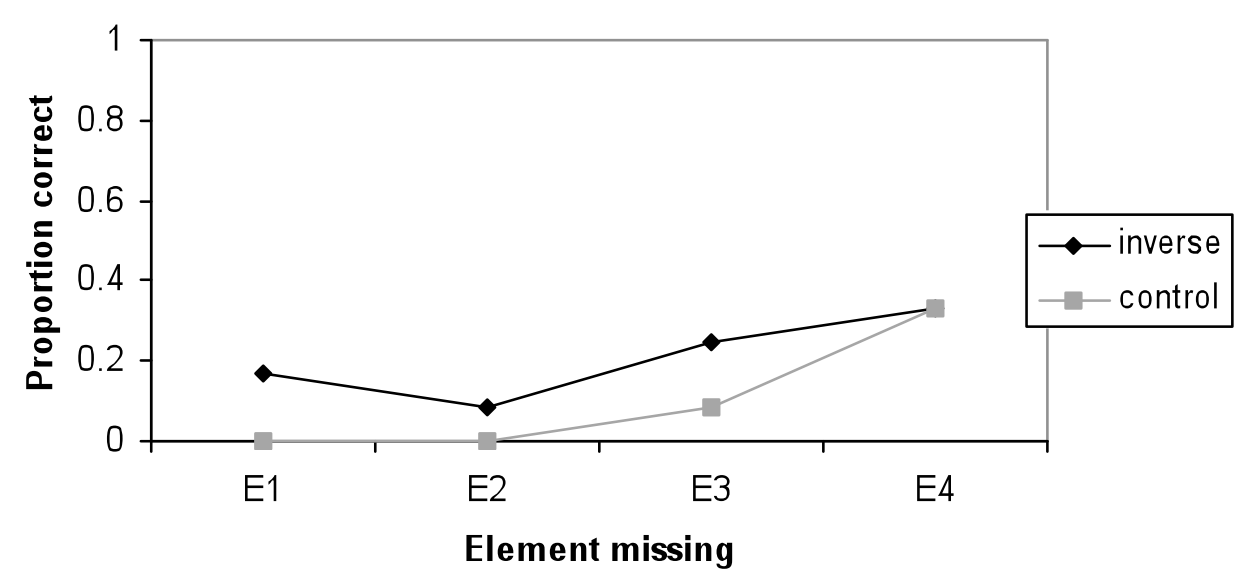

c) Inverse cluster $n=17$

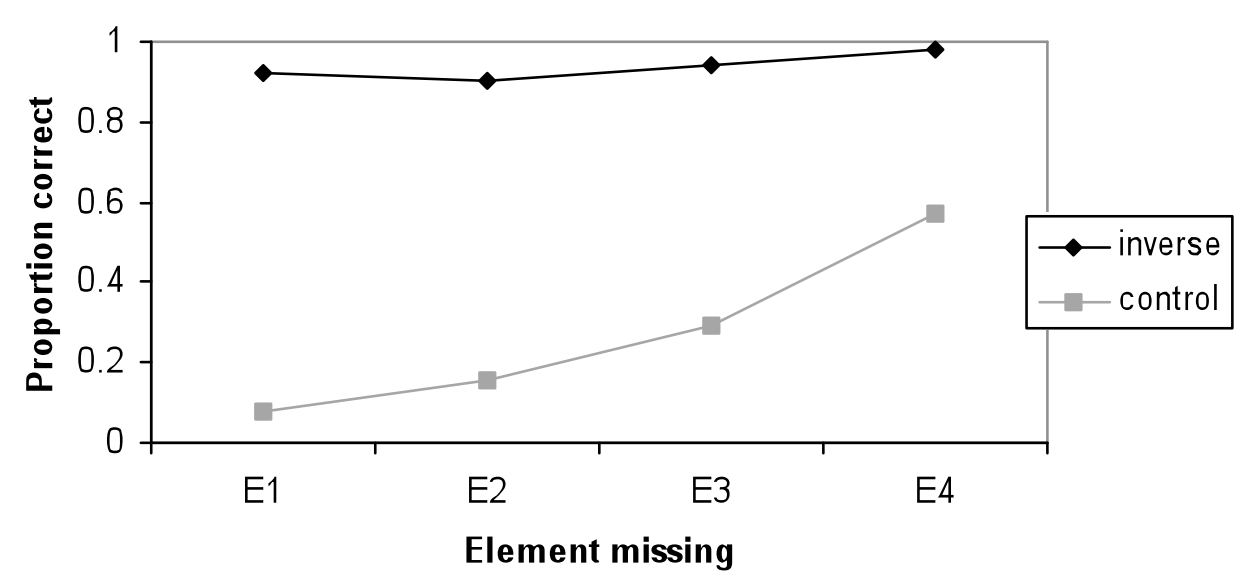


Appendix

Problems used in Experiment 1 and Experiment 2

Experiment 1

Inverse problems

[ ] $+12-12=18$

Control problems

[]$+9-9=26$

[ ] $+12-8=22$

[]$+7-7=13$

[ ] $+11-6=31$

$15+12-12=[]$

[ ] $+14-9=18$

$17+11-11=[]$

$11+11-7=[$ ]

$25+8-8=[]$

$21+9-13=[]$

$16+16-7=[]$

Experiment 2

Year 2

Inverse problems

[ ] $+6-6=8$

Control problems

[]$+9-9=13$

[ ] $+7-3=12$

[ ] $+7-7=10$

[]$+5-2=16$

$9+[]-5=9$

[ ] $+8-3=15$

$15+[]-7=15$

$9+[]-2=12$

$11+[]-8=11$

$12+[]-4=15$

$10+8-[]=10$

$9+[]-4=13$

$14+5-[]=14$

$11+11-[]=14$

$9+6-[]=9$

$10+9-[]=14$

$11+7-7=[]$

$12+8-8=[]$

$8+9-[]=11$

$8+8-5=[]$

$9+9-6=[]$

$13+6-6=[]$

$10+7-4=[]$

Year 4

Inverse problems

Control problems

[ ] $+12-12=18$

[ $]+12-8=22$

[ ] $+9-9=26$

[ ] $+11-6=31$

[] $+7-7=13$

[]$+14-9=18$

$13+[]-9=13$

$15+[]-5=19$

$21+[]-13=21$

$18+[]-8=23$

$24+[]-5=24$

$24+[]-11=18$

$16+14-[]=16$

$18+9-[]=13$

$19+8-[]=19$

$16+16-[]=24$

$22+7-[]=22$

$22+13-[]=28$

$15+12-12=[]$

$11+11-7=[$ ]

$17+11-11=[]$

$21+9-13=[]$

$25+8-8=[$ ]

$16+16-7=[]$ 